\title{
Commentary \\ Hypothermia and cardiac arrest: the promise of intra-arrest cooling
}

Roger A Band ${ }^{1,2}$ and Benjamin S Abella ${ }^{1,2}$

\begin{abstract}
${ }^{1}$ Department of Emergency Medicine, University of Pennsylvania, 3400 Spruce Street, Ground Ravdin, Philadelphia PA 19104, USA
${ }^{2}$ Center for Resuscitation Science, University of Pennsylvania, 3400 Spruce Street, Ground Ravdin, Philadelphia PA 19104, USA
\end{abstract}

Corresponding author: Benjamin S Abella, benjamin.abella@uphs.upenn.edu

Published: 22 April 2008

This article is online at http://ccforum.com/content/12/2/138

(c) 2008 BioMed Central Ltd

See related research by Bruel et al., http://ccforum.com/content/12/1/R31
Critical Care 2008, 12:138 (doi:10.1186/cc6845)

\begin{abstract}
Over the past several years, the implementation of therapeutic hypothermia has provided an exciting opportunity toward improving survival from out-of-hospital cardiac arrest. There are compelling data to support the prompt use of therapeutic hypothermia for initial survivors from out-of-hospital cardiac arrest, but animal data have suggested that initiation of therapeutic hypothermia during the intra-arrest period may significantly improve outcomes even further. In the first feasibility study in humans, Bruel and colleagues report on the implementation of this intra-arrest approach among patients suffering out-of-hospital cardiac arrest, an exciting prospect that is discussed in the present commentary.
\end{abstract}

In the last issue of Critical Care, Bruel and colleagues report findings from a small, prospective, observational study in which they investigate the feasibility, efficacy and safety of intra-arrest therapeutic hypothermia (TH) for victims of out-ofhospital cardiac arrest (OHCA) [1]. From an initial pool of 412 cardiac arrest victims, the study enrolled 33 patients with a variety of presenting rhythms. This represents the first study of its kind to investigate the feasibility of intra-arrest cooling in the clinical setting, an approach that has shown significant promise in animal models of cardiac arrest and brain injury [2-4].

Sudden cardiac arrest, defined as the abrupt loss of mechanical cardiac activity and concomitant global loss of blood flow, is a leading cause of death in the United States and Europe. Approximately 200,000 people suffer OHCA in the United States each year, and over $90 \%$ will succumb during resuscitation efforts or during subsequent hospitalization $[5,6]$. Survival to hospital discharge depends on a number of factors, including prompt delivery of cardiopulmonary resuscitation and defibrillation when indicated, the initial cardiac rhythm of arrest, and the quality of postresuscitation care including provision of $\mathrm{TH}$.
Despite the significant effort that has been invested in this field, few therapeutic or pharmacologic interventions have yielded meaningful increases in overall survival from $\mathrm{OHCA}$ over the past 20 years $[6,7]$. The relatively new and evolving treatment modality of $\mathrm{TH}$, however, has been associated with markedly decreased mortality and neurologic injury among patients who initially survive OHCA $[8,9]$.

$\mathrm{TH}$ reduces both the cerebral metabolic rate and oxygen demand, and it is thought to attenuate reperfusion injury, global inflammation and endothelial dysfunction - all consequences of cerebral and other organ ischemia $[10,11]$. Through such mechanisms, $\mathrm{TH}$ is thought to improve clinical parameters and outcomes. Two landmark multicenter randomized controlled trials of $\mathrm{TH}$ demonstrated over $20 \%$ absolute mortality reduction for initial survivors of ventricular fibrillation/ventricular tachycardia $\mathrm{OHCA}[8,9]$. Although both investigations documented strikingly improved survival in patients who had $\mathrm{TH}$ implemented after blood flow was restored, provocative animal data suggest that initiation of cooling during cardiac arrest itself may yield further considerable improvements in survival and neurologic outcome when compared with the current standard of delayed $\mathrm{TH}$. The feasibility of such an approach in humans remains an active question with a paucity of data.

The study by Bruel and colleagues examines the feasibility of conducting intra-arrest cooling in the prehospital setting [1]. Although other investigators have evaluated prehospital implementation of post-resuscitation hypothermia [12,13], the current study represents the first implementation of this novel therapeutic approach in humans during the intra-arrest period.

The current work establishes that $\mathrm{TH}$ induction during the intra-arrest period, using chilled medical saline during

$\mathrm{OHCA}=$ out-of-hospital cardiac arrest; $\mathrm{TH}=$ therapeutic hypothermia. 
advanced life support prehospital care, was feasible and without overt safety concerns. The technical and training hurdles in conducting such an investigation are formidable, and the authors should be applauded for their efforts. This study lays the foundation for future work on a larger scale that might incorporate randomization of patients to intra-arrest hypothermia, post-resuscitation hypothermia or normothermic resuscitation.

Furthermore, Bruel and colleagues' study demonstrates the feasibility of initiating intra-arrest hypothermia despite the significant, inherent challenges of the prehospital environment. The authors accomplished cooling with only peripheral venous access, although this may be technically more difficult during absence of flow (or limited flow during cardiopulmonary resuscitation), and may be very dependent on the quality of cardiopulmonary resuscitation and induced blood flow.

Finally, the study suggests that intra-arrest cooling in the prehospital environment may not only be feasible but also efficacious [1]. More specifically, the time to reach mild hypothermia $\left(34^{\circ} \mathrm{C}\right)$ was an impressive 16 minutes, substantially faster than other studies of post-resuscitation $\mathrm{TH}$. Although the sample size was small and the patient population was varied, $20 / 33(60.6 \%)$ of patients who were successfully cooled had circulation restored, a trend that suggests utility of cooling in the intra-arrest period. Despite successes in early cooling, there were surprisingly modest temperature differences at the time the patients were admitted to the intensive care setting. This should not be an insurmountable problem in future studies, and adjuncts to intravenous cooling could easily be used to maintain the hypothermic state.

One advantage of the European system that employed this protocol was the presence of an Emergency Medical Services physician and the ability to host the requisite refrigeration unit and associated equipment. This calls into question the ability to generalize this process to Emergency Medical Services systems without these resources, although it is likely that the tasks could be accomplished by skilled prehospital personnel without direct physician oversight. Finally, it is difficult to draw definitive conclusions about safety from this fairly limited study population. The overall number of enrolled patients was too small to detect differences in the appreciably rare complications, and it is not entirely clear over what time period the authors monitored for complications and what objective criteria were used to diagnose any observed adverse effects.

In summary, Bruel and colleagues' innovative study is the first to implement the use of $\mathrm{TH}$ prior to resuscitation from $\mathrm{OHCA}$. The authors demonstrate that prehospital, intra-arrest cooling is possible and may be efficacious. This notion is supported by our growing understanding of the pathophysiology of the ensuing injury associated with low or no-flow states. Mechanistically, early cooling may reduce reperfusion-related injury by attenuating the oxidant burst seen within minutes of normothermic reperfusion or by the inhibition of reperfusionactivated apoptotic pathways. Future studies should include objective measurements of patient pathophysiology to understand better the kinetics of injury and the beneficial effects of $\mathrm{TH}$.

\section{Competing interests}

The authors declare that they have no competing interests.

\section{References}

1. Bruel C, Parienti J-J, Marie W, Arrot X, Daubin C, Du Cheyron D, Massetti M, Charbonneau P: Mild hypothermia during advanced life support: a preliminary study in out-of-hospital cardiac arrest. Critical Care 2008, 12:R31.

2. Zhao D, Abella BS, Beiser DG, Alvarado JP, Wang H, Hamann KJ, Vanden Hoek TL, Becker LB: Intra-arrest cooling improves outcomes in a murine cardiac arrest model. Circulation 2004, 109:2786-2791.

3. Kuboyama K, Safar P, Radovsky A, Tisherman SA, Stezoski SW, Alexander H: Delay in cooling negates the beneficial effect of mild resuscitative cerebral hypothermia after cardiac arrest in dogs: a prospective, randomized study. Crit Care Med 1993, 21:1348-1358.

4. Markgraf CG, Clifton GL, Moody MR: Treatment window for hypothermia in brain injury. $J$ Neurosurg 2001, 95:979-983.

5. Thom T, Haase N, Rosamond W, Howard VJ, Rumsfeld J, Manolio T, Zheng ZJ, Flegal K, O'Donnell C, Kittner S, Lloyd-Jones D, Goff DC Jr, Hong Y, Adams R, Friday G, Furie K, Gorelick P, Kissela B, Marler J, Meigs J, Roger V, Sidney S, Sorlie P, Steinberger J, Wasserthiel-Smoller S, Wilson M, Wolf P; American Heart Association Statistics Committee and Stroke Statistics Subcommittee: Heart disease and stroke statistics - 2006 update. Circulation 2006, 113:85-151.

6. Eisenberg MS, Mengert TJ: Cardiac resuscitation. N Engl J Med 2001, 344:1304-1313.

7. Herlitz J, Bång A, Gunnarsson J, Engdahl J, Karlson BW, Lindqvist J, Waagstein L: Factors associated with survival to hospital discharge among patients hospitalised alive after out of hospital cardiac arrest: change in outcome over 20 years in the community of Goteborg, Sweden. Heart 2003, 89:25-30.

8. Bernard S, Buist M, Monteiro O, Smith K: Induced hypothermia using large volume, ice-cold intravenous fluid in comatose survivors of out-of-hospital cardiac arrest: a preliminary report. Resuscitation 2003, 56:9-13.

9. Hypothermia after Cardiac Arrest Study Group: Mild therapeutic hypothermia to improve the neurologic outcome after cardiac arrest. N Engl J Med 2002, 346:549-556.

10. Safar P, Xiao F, Radovsky A, Tanigawa K, Ebmeyer U, Bircher N, Alexander H, Stezoski SW: Improved cerebral resuscitation from cardiac arrest in dogs with mild hypothermia plus blood flow promotion. Stroke 1996, 27:105-113.

11. Hoesch RE, Koenig MA, Geocadin RG: Coma after global ischemic brain injury: pathophysiology and emerging therapies. Crit Care Clin 2008, 24:25-44.

12. Kim F, Olsufka M, Longstreth WT Jr, Maynard C, Carlbom D, Deem S, Kudenchuk P, Copass MK, Cobb LA: Pilot randomized clinical trial of prehospital induction of mild hypothermia in out-of-hospital cardiac arrest patients with a rapid infusion of 4 degrees C normal saline. Circulation 2007, 115:3064-3070.

13. Myers JB, Lewis R: Induced cooling by EMS (ICE). Year one in Raleigh/Wake County. J Emerg Med Serv 2007, 32:S13-S15. 